\title{
Swiss Split - a holistic approach to the distribution of containers to private sidings
}

\author{
Dirk Bruckmann $^{1,2} \cdot$ Patrik Dober $^{3} \cdot$ Albert Mancera $^{1} \cdot$ Irmhild Saabel $^{4}$. \\ Ulrich Weidmann ${ }^{1}$
}

Received: 24 January 2016 / Accepted: 2 November 2016 /Published online: 19 November 2016

(C) The Author(s) 2016. This article is published with open access at SpringerLink.com

\begin{abstract}
Purpose Swiss Split is a rail service in Switzerland which distributes containers via conventional shunting yards directly from intermodal terminals to the final recipients' sidings by rail. Today's Swiss Split service is quite successful, but it still has several weaknesses that reduce its competitiveness compared to container distribution by truck. Thus, the two main research questions were: Which feasible improvements for container distribution by rail can be determined? In how far do these improvements increase the competitiveness of container distribution by rail compared to container distribution by truck?

Methods The research bases on previous analyses regarding the weaknesses of container distribution by rail in Switzerland. For each of the identified weaknesses, suitable improvements were developed. The effects of these improvements were supposed to have an impact on the efficiency and the quality of the services. The improvements were then assessed by applying a cost model for rail freight and truck transportation. For this purpose, today's Swiss Split was modelled in a base case and the input data for the cost model (e.g., round trips per day for wagons, routing for the transports, train length and train utilisation) were changed according to the estimated effects of
\end{abstract}

This article is part of Topical Collection on The Future of rail freight transport and logistics

Dirk Bruckmann

dirk.bruckmann@hsrw.eu

1 ETH Zurich, Institute for Transport Planning and Systems, Stefano-Franscini-Platz 5, 8093 Zürich, Switzerland

2 Rhine-Waal University of Applied Sciences, Friedrich-Heinrich-Allee 25, 47475 Kamp-Lintfort, Germany

3 SBB Cargo AG, Bahnhofstrasse 12, 4600 Olten, Switzerland

4 Wascosa AG, Werftestrasse 4, 6005 Luzern, Switzerland the improvements. To finally estimate the impact of the improvements on the SWL production schemes, an agent based simulation for SWL was developed and applied.

Results The analysis of today's Swiss Split distribution by rail showed weaknesses in the fields of rolling stock, transhipment terminal structures and the production schemes for SWL. Thus, a new container wagon has been developed to serve the sidings. The terminal structure has been improved by a new gateway terminal. The production schemes for SWL have been improved by applying a train-coupling-and-sharing network structure and an improved schedule structure for SWL trains. An agent based simulation software for rail freight has been developed to assess the improvements in the production scheme. At last, the new business model for Swiss Split has led to an integration of transhipment processes and rail distribution. In sum all of these measures have resulted in significant cost reductions for the container distribution by rail. Conclusions The breakeven distance for Swiss Split compared to truck container distribution has been decreased from 140 to $70 \mathrm{~km}$. Hence, using SWL for final distribution has proofed to be competitive to trucking even for rather short distances. This shows that rail freight can be competitive compared to road transportation if a holistic approach which tackles all weaknesses of the existing services is applied.

Keywords Rail freight · Container · Hinterland transport . Single wagonload

\section{Introduction}

Shifting the transport of goods from road to rail and inland waterways is a major goal of European transport policy. Current research often focuses on the distribution of maritime containers by using combined transport or more specifically, 
on the usage of rail or inland waterways to serve hinterland terminals and the subsequent distribution of containers to recipients by truck. Very little research has considered using rail for the distribution of containers right up to the final recipients. In Switzerland, however, SBB Cargo still distributes a large number of containers directly to their final recipients by using the Swiss Split service. The research presented here aims at developing ideas that might help to improve the competitiveness of container distribution by rail. It presents a holistic approach that covers the entire transport chain. Many of these ideas will be implemented in an improved service called New Swiss Split as soon as the new Basel-Nord intermodal terminal will have been opened in 2019 .

This paper presents optimisation approaches and discusses their feasibility as well as their impacts on the distribution of containers by rail. Chapter 2 describes the current Swiss Split rail-based container distribution service including its current weaknesses. Chapter 3 presents a brief literature review on improving container distribution by rail. Chapter 4 describes the structure of the project and the work assigned to different project partners as well as the methodology that has been applied. Chapters 5 to 8 then describe the specific improvements that were developed for New Swiss Split followed by a description of the cost model and an analysis of the overall feasibility of New Swiss Split which refers to two case study examples in which this specific cost model has been applied. Chapter 10 finally presents conclusions and recommendations for further research.

\section{The existing Swiss Split service}

Swiss Split is a product of SBB Cargo used for the distribution of maritime containers to their final destinations by rail. Figure 1 illustrates the transport chain from the Swiss border up to the final recipient. Shuttle trains or barges transport

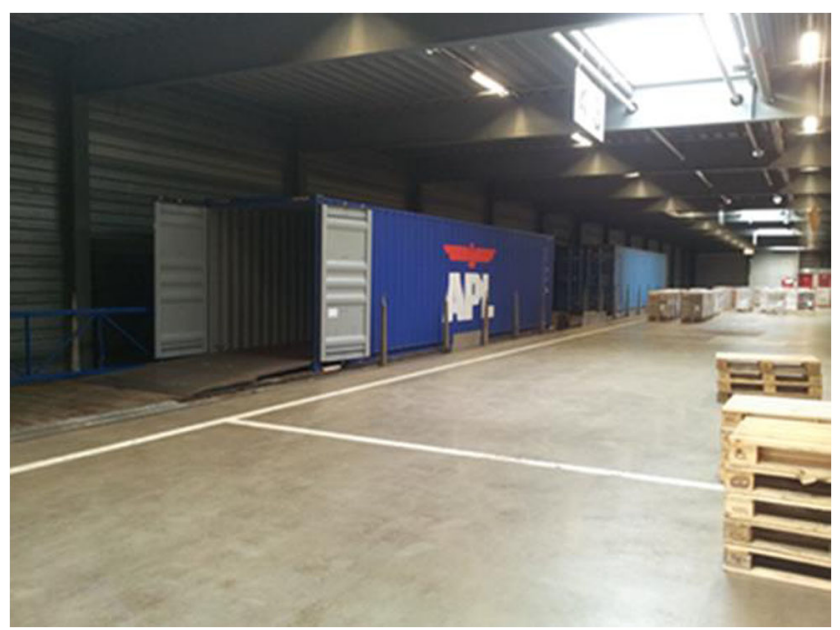

Fig. 1 Standard flat wagon with a Swiss Split container at the recipients' ramp (ETH Zurich) containers from seaports to the existing transhipment terminals in Switzerland. There, the containers are transhipped from long-haul trains or barges to standard flat-wagons or container wagons of the national single wagonload (SWL) network. From there the wagons are transported within the existing SWL production network of SBB Cargo to the final recipient's siding where they are placed at the existing loading ramps. Finally the containers are unloaded by forklifts or industrial trucks. Figure 1 shows the siding of Ikea in Lausen (next to Basel) as a sample siding.

Today's Swiss Split only covers the Swiss part of the rail transport to the final recipient, as shown in Fig. 2. Yet, the Swiss Split service is unique since no other country distributes maritime containers in single wagonload.

The analysis of SBB Cargo's shipment data for 2013 resulted in 53,600 containers that had been transported with 41,783 wagons using Swiss Split. Today SBB Cargo transports within the SWL network approximately 3,000 wagons per day, which means that Swiss Split represents about $6 \%$ of all transported wagons. Thus, Swiss Split partly assures the base utilization of the Swiss SWL network.

To evaluate and improve logistic chains in general, according to Mancera [1], logistic chains must be split up into their generic elements: loading and unloading, transport and transhipment. Figure 3 shows the generic transport chain of Swiss Split from the seaport (load) to the recipients' sidings (unload) including the transhipment at an intermodal hinterland terminal.

Improvements in form of an optimised business model can relate to each of the generic elements of the transport chain and/or to the coordination between these elements. Thus, an analysis of the weaknesses of each element of the transport chain is necessary. Based on this analysis, optimisation approaches can be defined.

While Swiss Split is a relatively successful product, there are several weaknesses that reduce its competitiveness compared to container distribution by truck. Bruckmann [2] has already identified the main Swiss Split weaknesses as follows:

- Very old rolling stock

- Widely dispersed terminal structure

- Business plan focuses only on the SWL transport link (i.e., does not include terminal operations or return of empty containers to depots)

- General SWL production scheme (affecting all SBB Cargo SWL products including Swiss Split).

Based on these weaknesses, analysis improvement approaches for Swiss Split were developed considering the generic elements of the transport chain, starting from the transhipment to the unloading at the final destination. The loading of the containers at the seaport and the rail transport from the seaport to the hinterland terminal will still not be carried out 


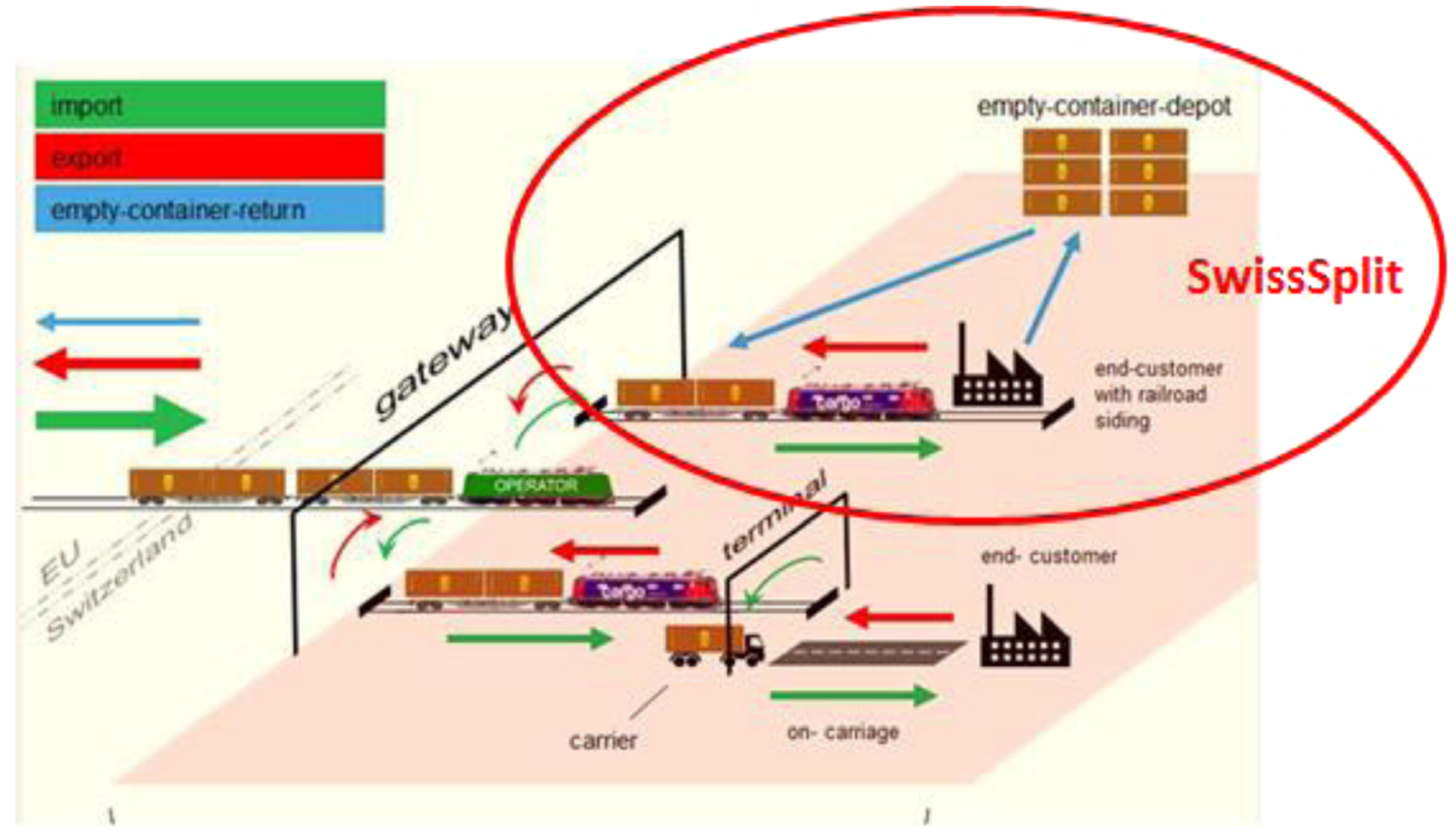

Fig. 2 Schematic diagram of the Swiss Split service (SBB Cargo)

by Swiss Split. Thus, the operational conditions and the costs for these parts remain unaffected.

\section{Literature review regarding general improvement approaches}

There is little literature on general approaches to improve an SWL based distribution of maritime containers since this is a unique Swiss product. Therefore the literature review focuses on each of the four improvement fields separately.

Generic Transport Chain, according to Mancera [1]
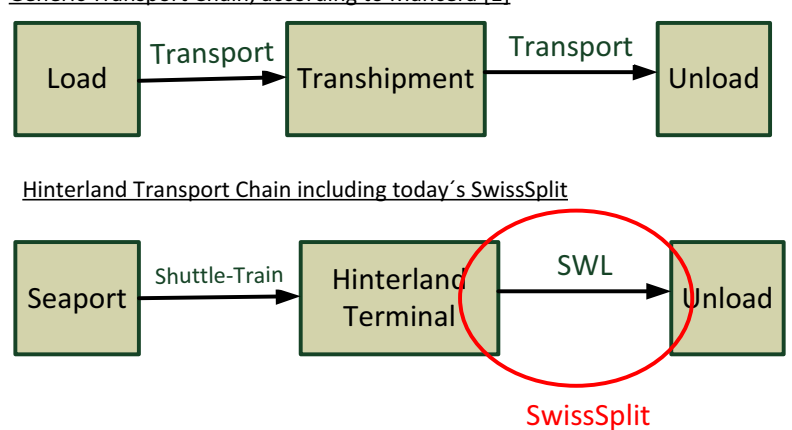

Hinterland Transport Chain including future NewSwissSplit

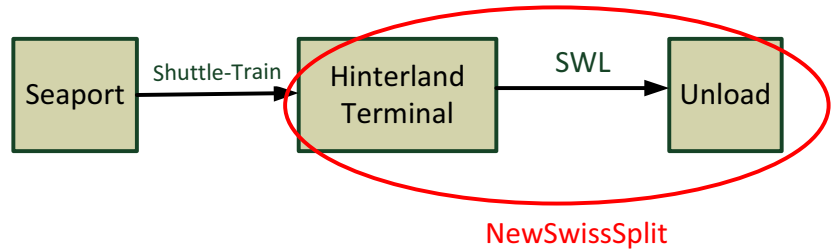

Fig. 3 Generic elements of an intermodal transport chain, according to Mancera [1] and transfer to the Swiss Split and New Swiss Split

\subsection{Rolling stock}

Again, there is not much literature analysing rolling stock improvements to facilitate the final distribution of containers to sidings due to the limited market for this type of service. One exception is the description of Swiss Split by the authors of this paper [3]. However, others have described general rolling stock improvements designed to improve the competitiveness of freight transport by rail. Their results are relevant for this research. Especially important are the results of König and Hecht [4] who describe a strategy for the further development of rolling stock in general as well as those of Eschweiler and Hecht [5] who analyse the influence of rolling stock on the market share of rail freight.

\subsection{Terminal structure}

Notteboom [6] states that bundling of container flows in consolidation terminals is one of the key driving forces of container network dynamics. Thus, a terminal network consisting of a few consolidation terminals is much more efficient than a structure of dispersed terminals (as it currently exists in Switzerland).

The EU research project TERMINET developed a model to optimize terminal locations and capacities [7]. Arnold et al. [8] evaluated a different methodology using a linear 0-1 approach. However, since these methods assume a final distribution of containers by truck, neither model fully addresses the optimization of rail-rail terminals since the network and cost structure of rail distribution is very different from the one of road distribution. 


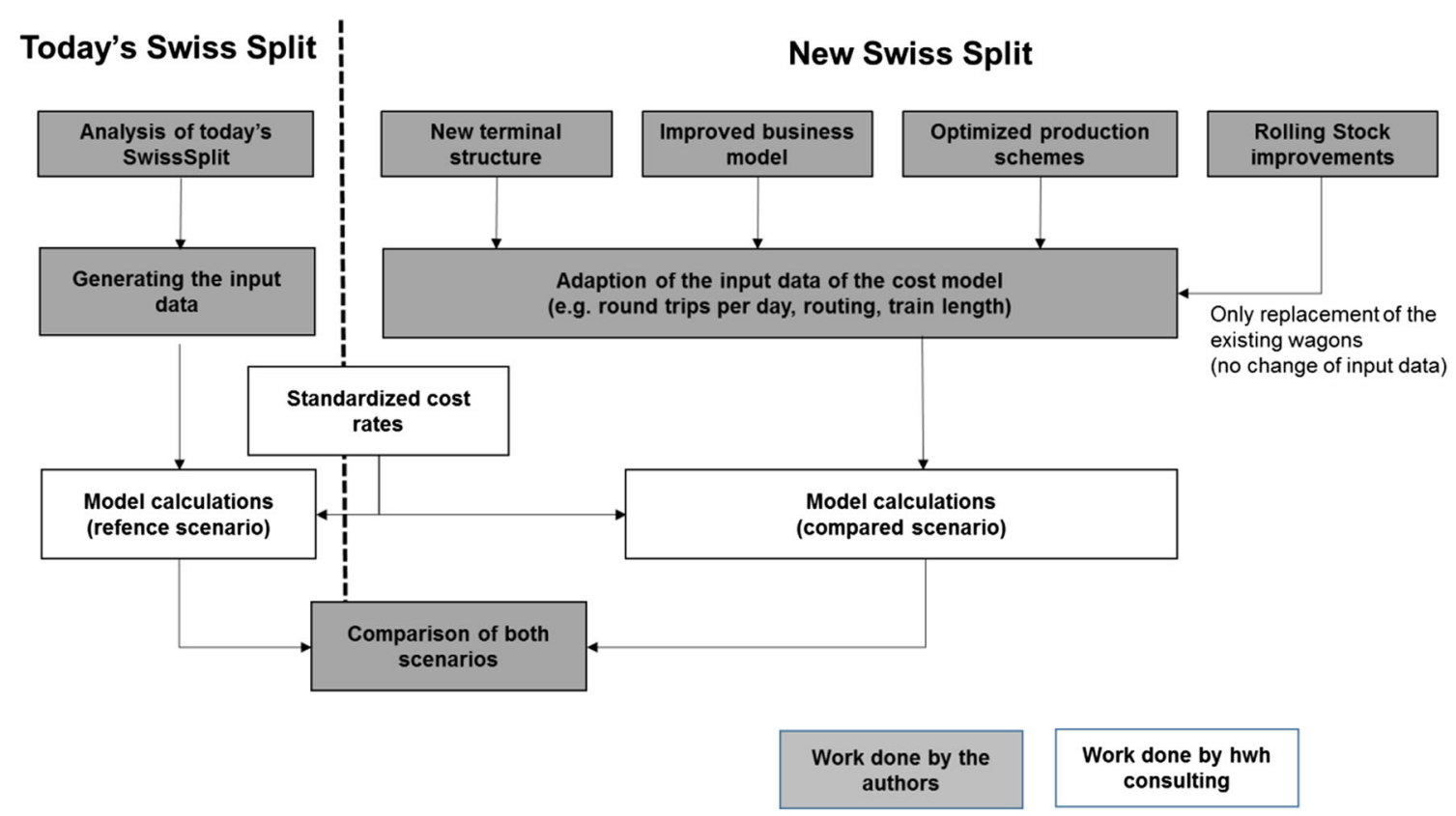

Fig. 4 Methodology used to model costs of "New Swiss Split” (ETH Zurich)

\subsection{Business plan}

There is no explicit mentioning of a transport chain vertical integration of the distribution of maritime containers by rail, but there are several papers on the vertical integration and collaboration within the overall supply chain (e.g., $[9,10]$ ). These papers find that integrating the entire transport chain leads to benefits. Bock [11] estimates the benefits of a real-time control of forwarder transportation networks as they are planned for New Swiss Split.

Some papers (e.g., $[12,13])$ address optimisations due to a collaboration of competing freight forwarders. These approaches are not applicable to Swiss Split since there are no competitors for the SWL service in Switzerland to cooperate with. Therefore, for Swiss Split, the vertical integration of several actors in the transport chain appears more promising than a horizontal integration. Furthermore, Moll [14] has already addressed an optimisation by an integrated planning of freight transports including a collaboration of shippers and railway freight operators $\mathrm{He}$ stated that collaboration generates a large potential to increase the efficieny of rail transport. But nowadays due to a lack of communication and missing information this potential cannot be leveraged. Thus, an integrated approach as planned in New Swiss Split is a feasible approach to improve the competitiveness of rail transport.

Wittenbrink et al. [15] suggested a vertical disintegration of SWL to improve the competition in the market. This approach

Fig. 5 Distribution of wagon $25^{\prime} 000$ types at Swiss Split in 2013 (SBB

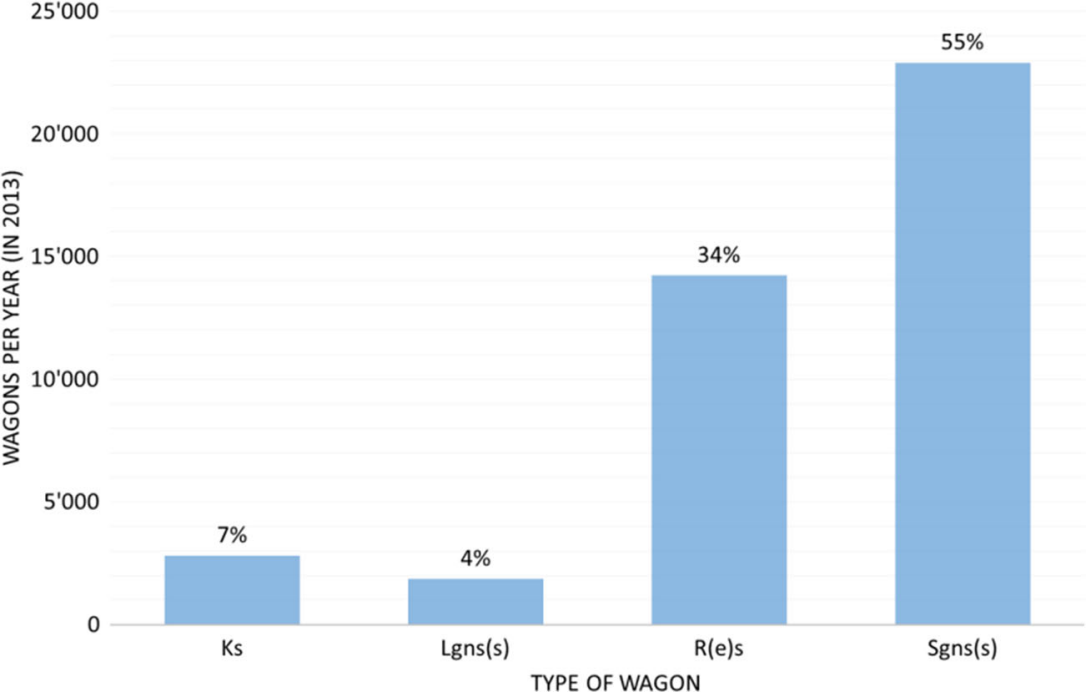



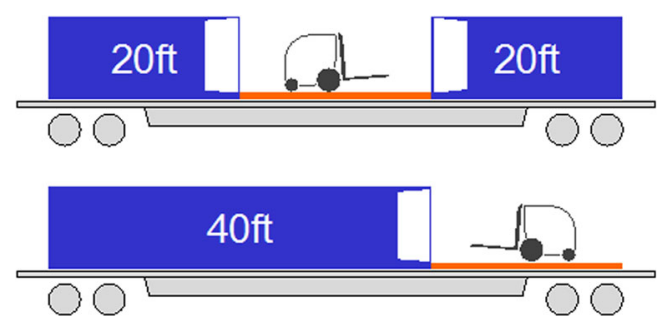

Fig. 6 Loading schemes for containers on a Swiss Split wagon (ETH Zurich)

is unlikely to improve the container distribution for Swiss Split because there is insufficient demand to operate a second similar distribution network.

\subsection{SWL production schemes}

The quality of rail transport is significantly improved when the product design considers the requirements of the entire door to door service [16]. This approach generally leads to the development of multimodal transport chains and a final distribution by truck. However, the single wagonload rail service is a form of door-to-door transport, too. General approaches towards an optimisation of SWL production schemes are mentioned by Marin and Salmeron [17, 18]. Following these publications several authors have described SWL optimization approaches using operations research methods. For example, Ceselli et al. [19] optimized the Cargo Express Service as a part of the Swiss SWL network. Bruckmann [20] evaluated the containerization of the conventional SWL and the replacement of conventional shunting yards by container terminals.

The weakness of all existing optimization algorithms is that they do not take railway network capacity restrictions into account. This is especially problematic in densely used rail networks where limited train-paths are available [21]. Therefore, infrastructure capacity restrictions must be considered in the development of an optimized SWL production scheme.

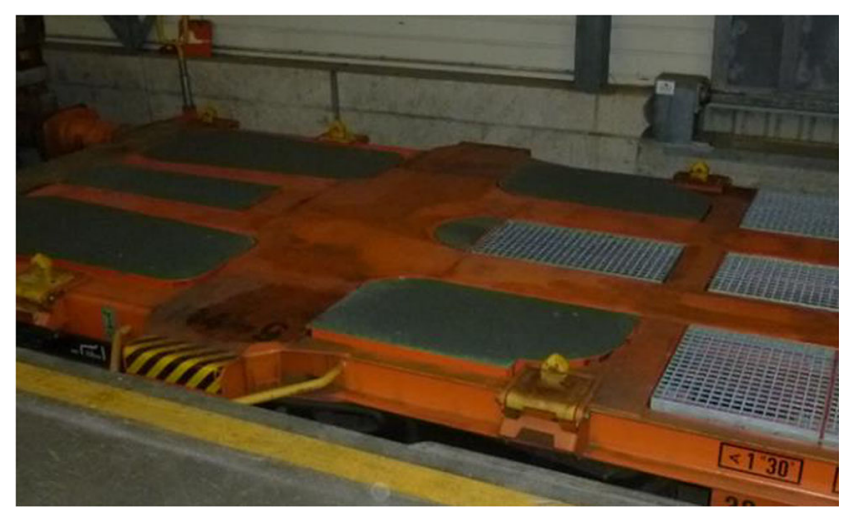

Fig. 8 Swiss Split wagon with inlay elements (Wascosa)

\section{Methodology}

This study evaluated the current Swiss Split service, developed ideas to improve the service and then tested these ideas using a cost model. The cost model was used to evaluate both, the feasibility of specific improvements and the optimization of the entire New Swiss Split production concept. Figure 4 shows the methodological approach and the assignment of tasks to project partners.

The authors were responsible for the analysis of the railway production changes that could be achieved by specific improvements in the four improvement areas:

- Rolling stock

- Terminal structure

- Swiss Split business model

- SBB Cargo SWL production scheme

These railway production data were then entered into a cost model developed by an external consultant to evaluate the financial benefits of the improvements. The next four sections describe the proposed improvements in each of these four areas. Section 9 describes how these improvements were integrated into the model and presents the results of the two case studies.

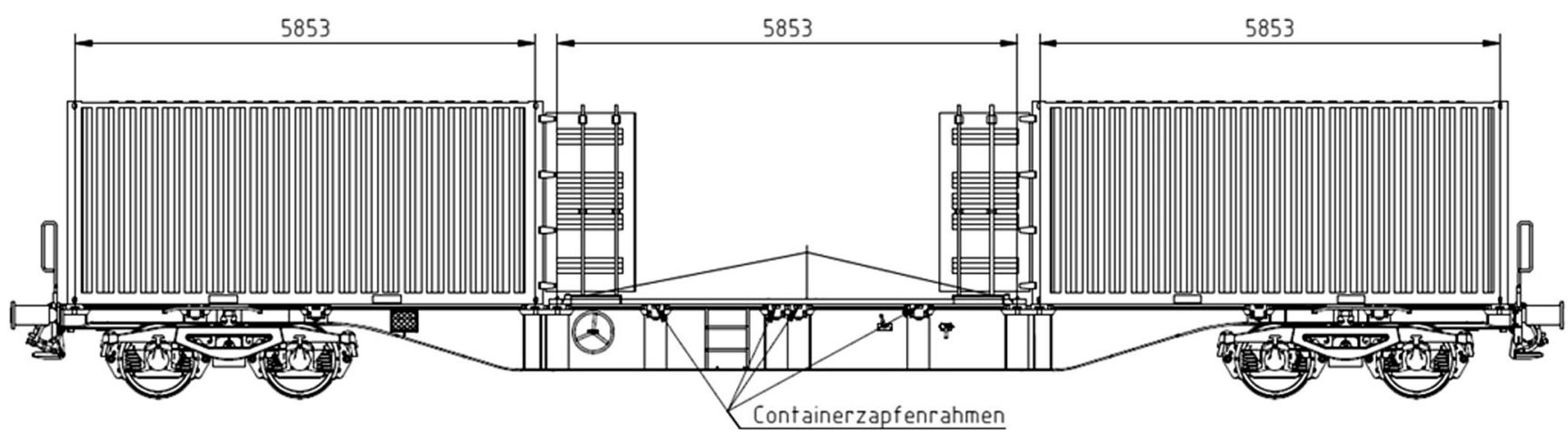

Fig. 7 Swiss Split wagon with two 20-ft containers and platform (SBB Cargo/PVF Schienenfahrzeuge) 
Fig. 9 Height of the ramps [mm over track height] (Wascosa)

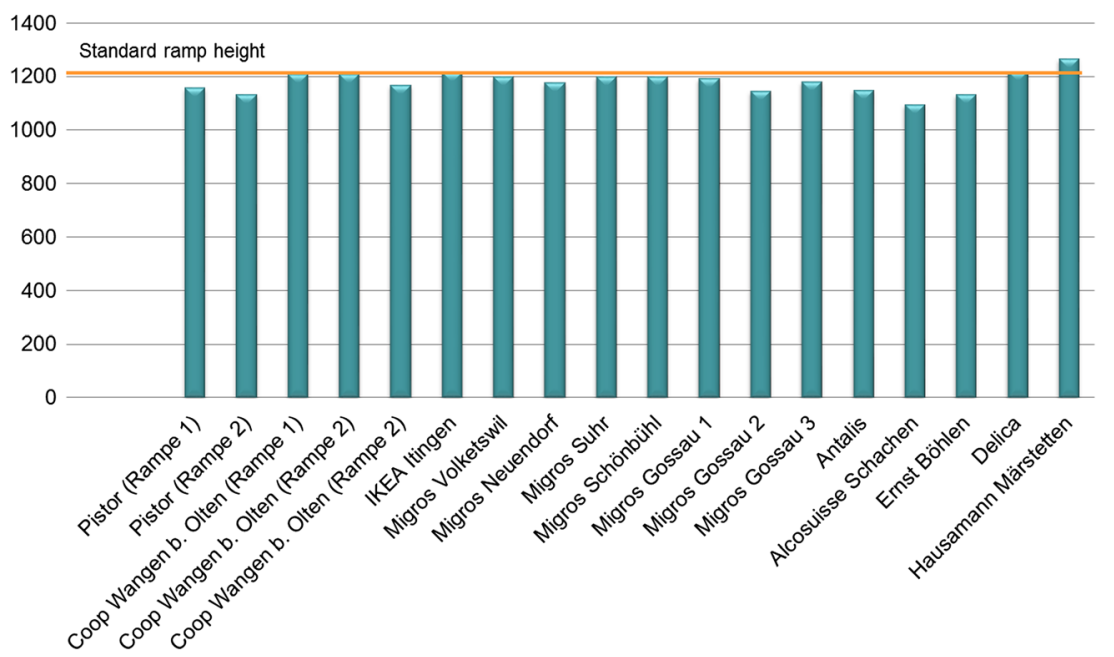

\section{Improved Swiss Split rolling stock}

\subsection{Existing Swiss Split rolling stock}

Today two general types of rolling stock are used for Swiss Split: standard flat wagons with wooden floors and conventional container wagons. Both types include two and four axle versions. The big difference between these vehicle types is that container wagons have no floor. This means loading and unloading equipment (e.g., forklifts) is unable to operate on these container wagons. Thus, additional equipment such as moveable ramps is required to load/unload the containers. Therefore a moveable ramp replaces the missing floor of the container wagons.

More specifically, the following types of wagons are currently being used for Swiss Split:

- Two-axle standard flat wagons with a wooden floor, type Ks;

- Four-axle standard flat wagons with a wooden floor, types Res and Rs;
- Two-axle container wagons, type Lgns and Lgnss;

- Four-axle container wagons, types Sgns and Sgnss.

Figure 5 illustrates the distribution of wagon types at Swiss Split for the year 2013. As shown, approximately $59 \%$ of the Swiss Split wagons are standard container ones, but about $41 \%$ are still old wooden floor flat wagons.

The type of wagon which is used depends on the technical equipment that is available for the unloading of containers at the destination sidings. Larger sidings are generally equipped with specific loading equipment to load and unload the containers. These sidings can be served with container wagons. On the other hand, smaller sidings often only have forklifts or industrial trucks available to unload containers. These vehicles need a continuous floor to operate on the wagon. Therefore, these sidings can only be served by conventional flat wagons.

Today, the flat wagons with wooden floors have become uneconomical and this is why SBB Cargo would like to develop more efficient wagons for Swiss Split. Since containers are fixed by nailed wooden blocks, it is complicated to secure them. So the main idea was to replace the flat wagons by
Fig. 10 Vertical distances between track axis and ramp edge [mm] (Wascosa)

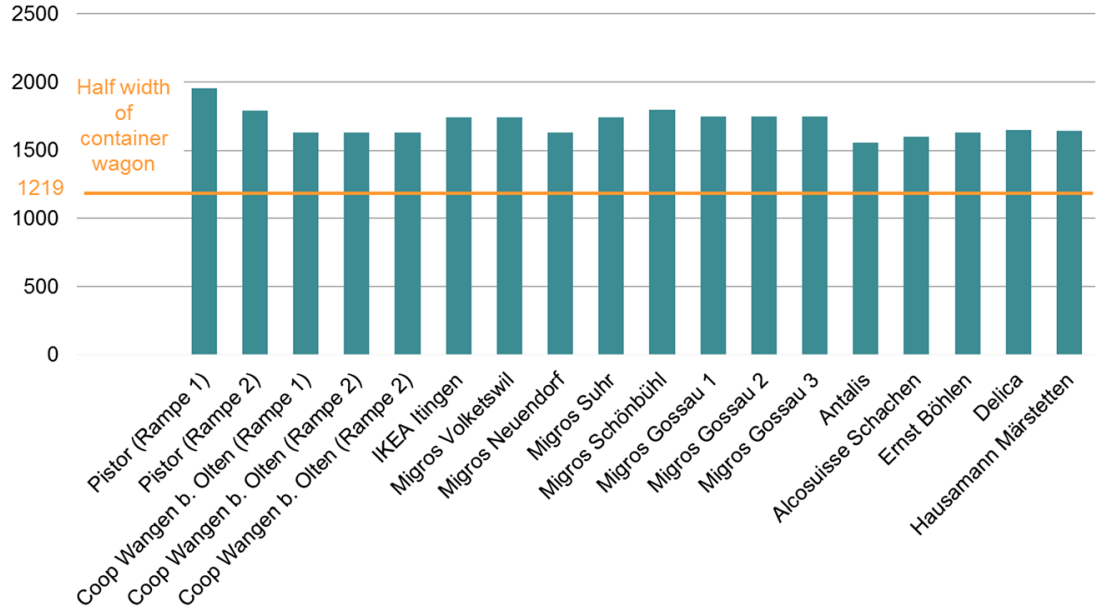




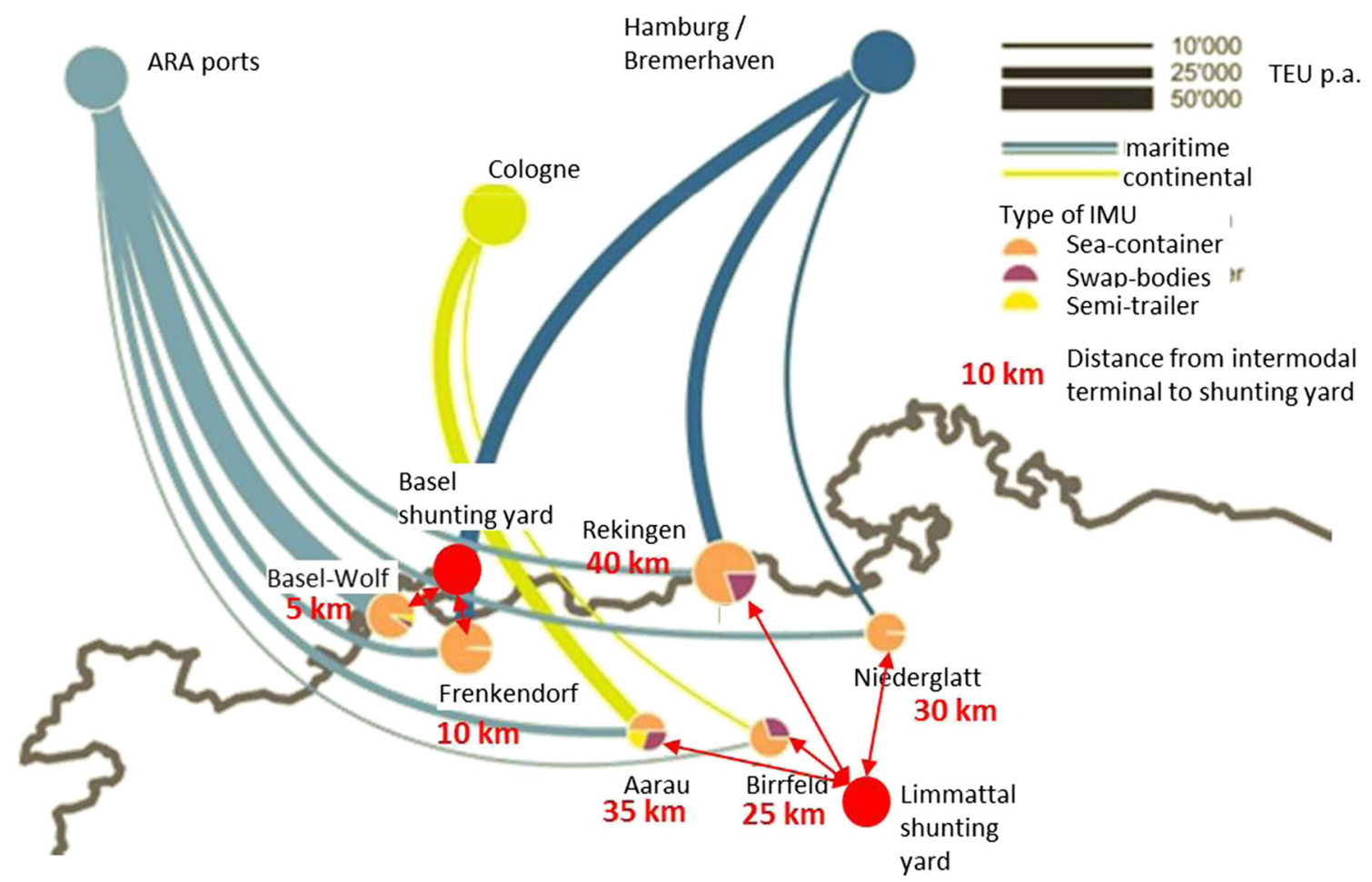

Fig. 11 Terminal structure and transport flows for combined transport in Switzerland in 2010 (Ickert et al., 2012)

modified container wagons. The next section describes the development of these new wagons.

\subsection{Specifications for an improved Swiss Split rolling stock}

As part of the ViWaS project, new wagon designs were developed for Swiss Split. The new wagons were designed to improve both the loading/unloading process on sidings and the transhipment process in terminals. The goal was to improve the service without increasing wagon-costs.

The new wagons had to be able to meet all customers' needs when serving a siding with a container. The main requirements for the new wagons were:

- All possible loading schemes with 20- and 40-ft containers had to be covered (Fig. 6).

- The tare of wagons should not increase significantly.

- No additional equipment should be required in sidings for loading/unloading wagons.

As most of the current Swiss Split shipments are transported on four-axle wagons $(89 \%)$ or on conventional container wagons ( $4 \%$ ) there is only very low demand $(7 \%)$ for a new designed two axle wagon. Thus, the New Swiss Split wagon was designed only as a four-axle wagon.

The main concept was to modify standard container wagons for a new use in the Swiss Split service. Therefore the authors developed specifications for two prototype wagons:
- Platform Alternative: The platform alternative placed a modular platform on the container wagon to fully cover it. The platform consisted of $20-\mathrm{ft}$ modules, which were connectable, so that the modules covered the entire wagon length. The platform was equipped with corner fittings to fix the containers. The platform could only be removed in a workshop. The height and width of the wagon including the platform was approximately the same as of a conventional flat wagon. The platform itself rested on top of the container wagon and was slightly wider than the container wagon itself (Fig. 7).

- Inlay Alternative: The inlay alternative installed inlay elements to fill the spaces between the containers on the floor of the wagon (Figs. 8 and 9). The height and width of the container wagon remained the same.

One of the main problems when replacing conventional flat wagons with standard container wagons is that container wagons (width: $2438 \mathrm{~mm}$; height: $1155 \mathrm{~mm}$ ) are narrower and lower than flat wagons (width: $2650 \mathrm{~mm}$; height: 1230 to $1260 \mathrm{~mm}$ ). Since the new wagons had to be designed to meet customers' needs, the authors visited 18 Swiss Split customer sidings in Switzerland to measure the ramp height and vertical distance on site. They also studied operations and discussed the wagon requirements with company logistic managers.

The standards for the design of transhipment facilities recommend a ramp height of $1200 \mathrm{~mm}$ over track and a vertical distance between the track axis and the ramp edge of $1700 \mathrm{~mm}$ 


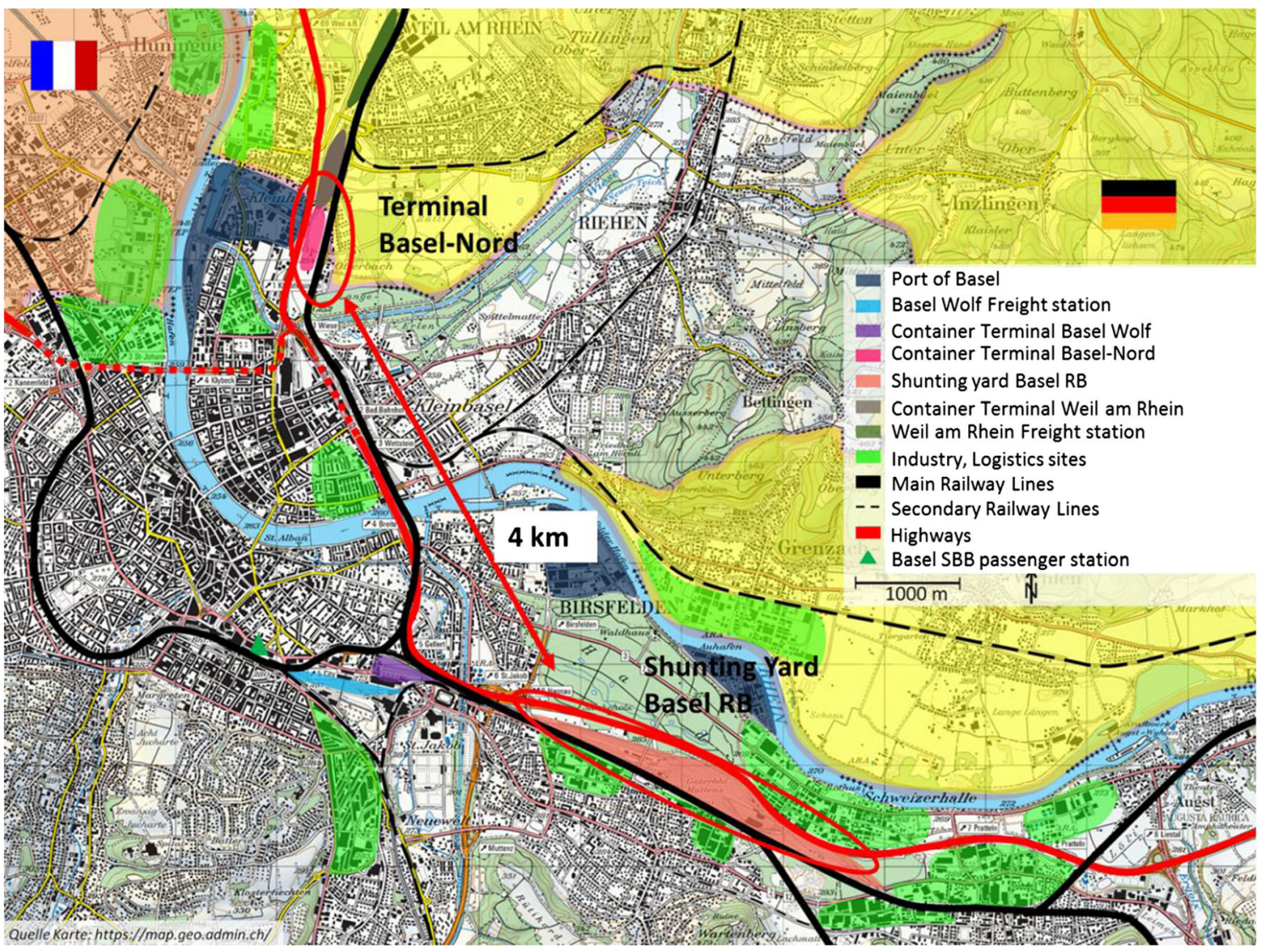

Fig. 12 Location of the new Gateway Terminal Basel-Nord (ETH Zurich)

[22]. As shown in Fig. 9, most ramps in Switzerland have a height of approximately $1200 \mathrm{~mm}$. Only very few ramps in Switzerland are slightly lower or higher.

As shown in Fig. 10, the vertical distances between track axes and ramps are between 1500 and $1950 \mathrm{~mm}$.

Thus, the platform alternative could generally be used in all sidings similar to conventional flat wagons. However, the inlay alternative, since it is narrower and lower in height than the existing flat wagons, would require additional equipment (e.g., bridging plates) on the sidings to cover the distance between wagon and ram. So there is either the opportunity of choosing the lightweight inlay alternative which requires additional equipment at the siding or the platform alternative with higher tare.

Once the specifications had been checked with regards to the dimensions of different customer sidings, they were used by SBB Cargo and Wascosa (a rail transport operator) to develop two different prototype wagons. These prototypes are now being tested in real Swiss Split transport operations and the results will be used to further improve the wagon design. The first results have shown already that both solutions are generally suitable to replace the existing flat wagons.

The on-board intelligence of the wagons will include a GPS location module and a data logger, so that the wagons can be located easily. Due to the exact information about the position of the wagons, they can be dispatched more easily. Thus, together with the new integrated business model, the round trip times of the wagons from nowadays approximately 3 days shall be reduced to 2 days. Furthermore the mileage counting will facilitate a mileage-based maintenance of the wagons.

In the next steps additional modules like a surveillance of the load status of the wagon, sensors to detect condition of the payload, weight sensors to measure the axle loads or equipment for automatic brake tests will be integrated. This will support the goal to reduce the staff required at sidings and regional stations. The loading platform will be equipped with a GPS module, too. Thus, the risk of a loss or theft of the platforms is reduced by far.

\section{The new terminal structure in Switzerland}

Intermodal rail freight terminals are widely dispersed in Switzerland today. The existing terminals are small-tomedium size with a capacity between 30,000 to 50,000 TEU per year, equating 150 to 250 TEU per day [23]. As shown in Fig. 11, transport flows are also relatively dispersed.

This terminal structure makes it relatively inefficient to transfer containers from intermodal terminals to the shunting yard. Each terminal uses Swiss split only for a few containers per day so that the trains to the shunting 


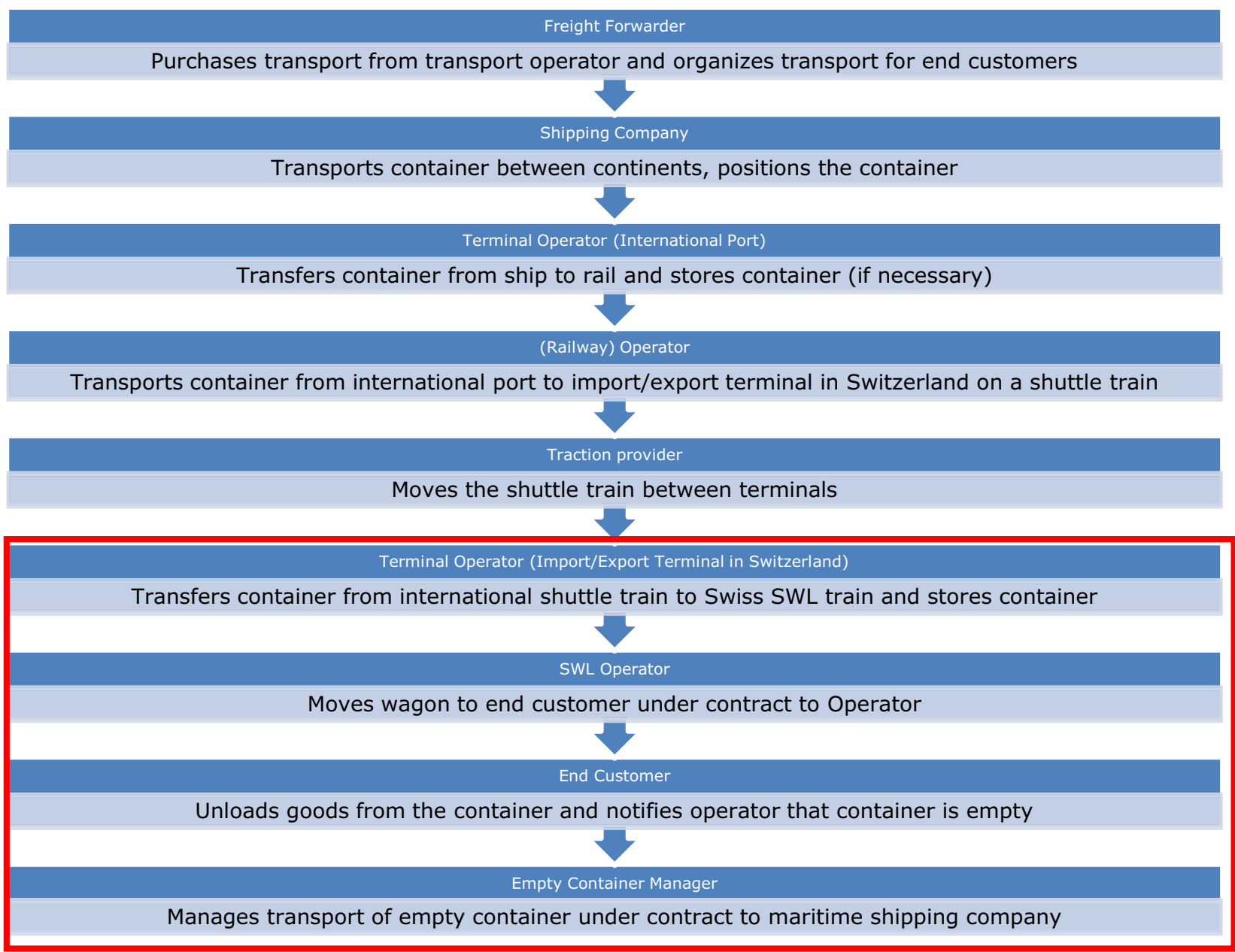

Fig. 13 Intermodal chain for combined transport in Switzerland (ETH Zurich)

yard are quite short. In addition, the distances from the different terminals to the next shunting yard are quite long-sometimes up to $40 \mathrm{~km}$. That makes the transfer of containers within the SWL network quite expensive and in result the terminals are served only once a day. Due to this inefficient use of container wagons, transport times and costs for Swiss Split are increased.

Several studies were carried out that aimed at an optimisation of terminal structures. Ickert et al. [23] analysed terminals in terms of the present and future demand for container distribution in Switzerland. There are very few potential sites for large terminals in Switzerland due to its strong land use planning regulations. Therefore an operations research approach to optimise the terminal structure would have been insufficient. Instead, it is necessary to conduct a qualitative comparison of the few potential terminal sites available. Such an analysis was carried out and results were discussed with the logistics sector in order to define a common strategy [24].

SBB Cargo's goal is to improve the terminal structure in Switzerland by introducing one main gateway terminal, where all containers for Swiss Split can be collected. Therefore a new trimodal (rail - road - inland waterway) terminal in Basel with a capacity of up to 1,000 TEU per day is planned. This terminal is supposed to be served directly from seaports and most of the Swiss Split transhipments shall be concentrated there. But even this new terminal will be operated with conventional transhipment technologies. Up to now an automation of cranes or terminal vehicles has not been considered. If automation will ever be realized is unpredictable. Hence, the assessment of New Swiss Split only considers improved terminal operations with conventional transhipment technologies.

Nevertheless, the new terminal will increase the efficiency of transhipments from long haul shuttle-trains to the SWL wagons by far. If demand increases, more and longer transfer-trains will be operated to serve the shunting-yard. Another advantage is that the distance between terminal and shunting-yard will only be approximately $4 \mathrm{~km}$ compared to nowadays up to $40 \mathrm{~km}$. Figure 12 shows the location of the new Basel gateway terminal and shunting yard. 


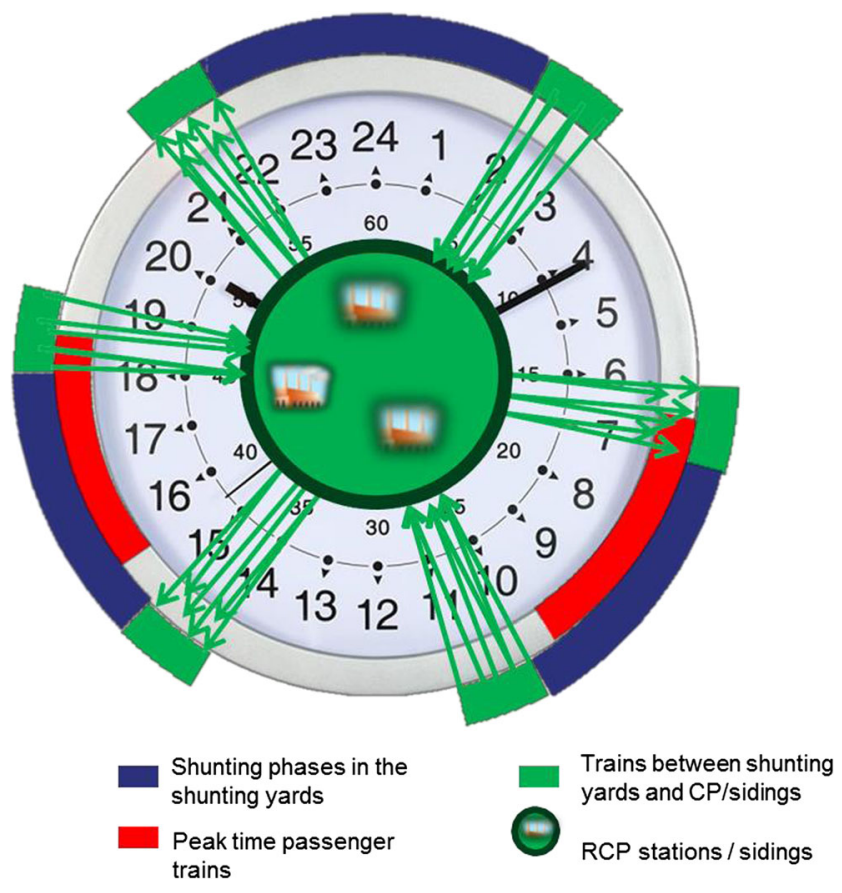

Fig. 14 New structure of the SBB Cargo production schemes in 2017 (SBB Cargo)

\section{Improved Swiss Split business model}

Intermodal transport chains are complex by nature since they include many actors and many different activities. Figure 13 illustrates a typical intermodal transport chain for containers that arrive at a European seaport and are transported to or from Switzerland. New Swiss Split will cover the entire container distribution processes in SWL within Switzerland. As can be seen, the movement and storage of empty containers is also part of the system. The figure highlights the Swiss Split part of the chain.

Due to the terminal operator, the SWL operator and the operators of the empty container depots are currently different entities, each of them optimizing their own process chain without considering the other partners' process chains.

SBB Cargo has developed a new business model for the Swiss Split service that integrates all parts of the process chain into a single product. This means that the entire distribution process from the hinterland terminal to the end customer including the return of the empty container to a depot is optimized. In the new model terminal operations, container movements and container wagons are dispatched from a single source. This will improve efficiency by, for example, increasing the number of round trips per week for container wagons used in Swiss Split from one to two or three a week in future.

In summary, optimising the entire Swiss Split process eliminates inefficiencies in the transport chain and helps to increase competitiveness compared to a road distribution of containers.

\section{Optimization of SWL production schemes}

SBB Cargo plans to improve the feasibility and flexibility of the entire SWL network in Switzerland. As part of these improvements, today's production scheme of one overnight service between all sidings needs to be increased to a continuous production scheme operating $24 \mathrm{~h}$ a day. In the future, SBB Cargo will serve sidings up to three times a day. The assets including mainline locomotives and shunting yards will be in continuous use. This will significantly increase the asset productivity and reduce the use of infrastructure on mainlines in peak periods for passenger trains since most of the shunting on the shunting yards will take place then. Figure 14 illustrates the new production scheme structure.

The authors have tested several additional improvements to the future production scheme using an agent based simulation [25]. Under the current standard production scheme, for example, trains only serve one regional shunting station (RCPTeam). In the future, the application of new traction technologies with smaller bi-power locomotives and improved freight wagons with on-board intelligence will allow an efficient introduction of a train-coupling-and-sharing production scheme [26]. In this case trains may consist of two parts for two different RCP-stations. At an intermediate stop the train parts can be split easily and each train can continue to its final RCP destination independently. This is illustrated schematically in Fig. 15.

The first simulation results have shown that this production scheme could significantly reduce train kilometres and wagon kilometres for the overall production of the SWL. Thus, this optimization will further improve the overall SWL system.
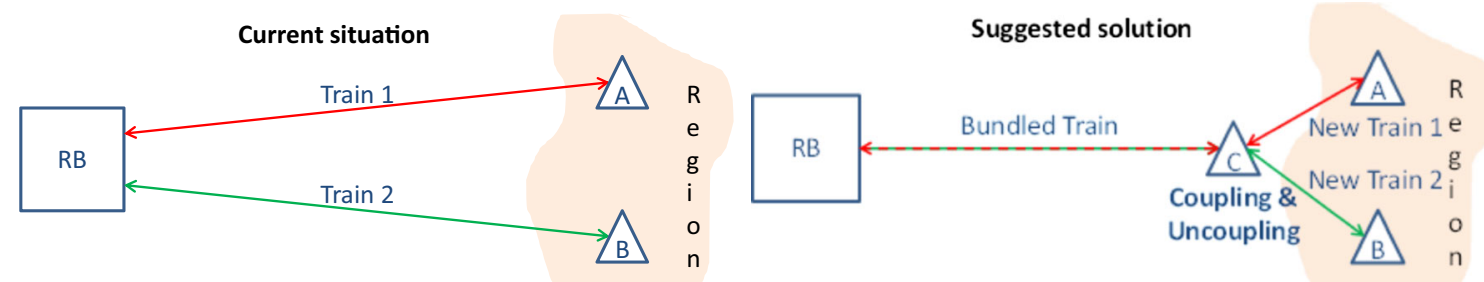

Fig. 15 Current and suggested situation for the production schemes (ETH Zurich) 
Table 1 Improvement approaches for Swiss Split and their influence on the generic elements of the transport chain

\begin{tabular}{llll}
\hline Weakness of current Swiss Split & Improvement approach & Influenced element of the transport chain \\
\cline { 3 - 4 } & & Unload & Transport \\
\hline Very old rolling stock & Development of a new Swiss Split-Wagon & $\mathrm{X}$ & $\mathrm{X}$ \\
Widely dispersed terminal structure & New gateway terminal & $\mathrm{X}$ & $\mathrm{X}$ \\
Business plan focuses on SWL transport & New business model, covering the entire transport chain & $\mathrm{X}$ & $\mathrm{X}$ \\
SWL production scheme & Improved SWL production scheme & & $\mathrm{X}$ \\
\hline
\end{tabular}

\section{New Swiss Split feasibility analysis}

\subsection{Cost model}

The overall feasibility of the improved Swiss Split service was tested using a cost model. The authors developed railway production data to model the proposed improvements in rolling stock, terminal structure, the Swiss Split business model and SWL production improvements. For example they developed a modal-split model for the container distribution in Switzerland and assigned container flows to specific terminals. The resulting container flows were integrated into the

Table 2 Components of the transport cost model

\begin{tabular}{|c|c|c|c|}
\hline Transport segment & Cost component & Cost basis & Comments \\
\hline \multicolumn{4}{|l|}{ Railway transport } \\
\hline \multirow{2}{*}{$\begin{array}{l}\text { Shunting in the origin and } \\
\text { destination terminal }\end{array}$} & Locomotive (leasing + maintenance) & CHF / operational hour & - \\
\hline & Staff (engine driver + shunter) & $\mathrm{CHF}$ / operational hour & Depends on the salary level of staff \\
\hline Shunting in shunting yards & Shunting fee of the infrastructure operator & $\mathrm{CHF}$ / shunted wagon & Only for single wagonload \\
\hline \multirow{5}{*}{$\begin{array}{l}\text { Main line operation (each segment } \\
\text { siding }->\text { shunting yard, shunting } \\
\text { yard }->\text { shunting yard, Shunting } \\
\text { yard }->\text { siding) }\end{array}$} & Locomotive (leasing + maintenance) & $\mathrm{CHF} /$ day & - \\
\hline & Rolling stock (leasing + maintenance & $\mathrm{CHF} /$ day & - \\
\hline & Engine driver & $\mathrm{CHF} /$ hour & \\
\hline & Energy & $\mathrm{CHF} /$ ton-km & $\begin{array}{l}\text { Applies only if not included in the } \\
\text { track access fees }\end{array}$ \\
\hline & Train access fees & $\mathrm{CHF} /$ train-km & $\begin{array}{l}\text { Depends on the train-weight and } \\
\text { access fee of the infrastructure } \\
\text { operators involved }\end{array}$ \\
\hline \multicolumn{4}{|l|}{ Road transport } \\
\hline \multirow[t]{6}{*}{ Transportation } & Truck (leasing) & CHF/day & - \\
\hline & Truck (maintenance) & $\mathrm{CHF} / \mathrm{km}$ & - \\
\hline & Truck Driver & CHF/hour & Depends on the salary level of staff \\
\hline & Road access fees & $\mathrm{CHF} / \mathrm{km}$ & Depends on the country and the road-type \\
\hline & Fuel & $\mathrm{CHF} /$ litre & $\begin{array}{l}\text { An optimized fuel strategy was assumed } \\
\text { (e.g., buying fuel in countries with } \\
\text { low fuel-taxes) }\end{array}$ \\
\hline & Tires & $\mathrm{CHF} / \mathrm{km}$ & - \\
\hline \multirow[t]{2}{*}{$\begin{array}{l}\text { Border procedures at the customs } \\
\text { (waiting time) }\end{array}$} & Truck (leasing) & CHF/Day & $\begin{array}{l}\text { The waiting time causes less round trips } \\
\text { per day, applies at the Swiss-German } \\
\text { and Swiss-French-Border }\end{array}$ \\
\hline & Driver & CHF/hour & \\
\hline \multicolumn{4}{|l|}{ Inland waterway transport } \\
\hline Overall costs & \multicolumn{3}{|l|}{$\begin{array}{l}\text { The overall costs for a container transport } \\
\text { were provided by a container shipper }\end{array}$} \\
\hline \multicolumn{4}{|l|}{ Transhipment costs in the terminal } \\
\hline Overall costs & \multicolumn{3}{|c|}{$\begin{array}{l}\text { Calculated by a specific transhipment cost-model, } \\
\text { developed by the institute of transport planning } \\
\text { and systems. The model includes the investments } \\
\text { for the terminal (depreciation and interest), the } \\
\text { staff costs, energy and maintenance. }\end{array}$} \\
\hline
\end{tabular}


Fig. 16 Transport costs per container from Rotterdam to Lausen (ETH Zurich)

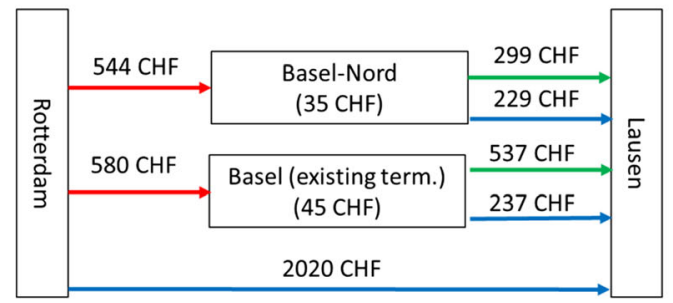

\begin{tabular}{|l|c|}
\hline Transport route & Overall costs \\
\hline Optimized Swiss Split & $878 \mathrm{CHF}$ \\
\hline Trucking via BS-Nord & $808 \mathrm{CHF}$ \\
\hline Swiss Split today & $1^{\prime} 162 \mathrm{CHF}$ \\
\hline $\begin{array}{l}\text { Trucking via existing } \\
\text { terminals }\end{array}$ & $862 \mathrm{CHF}$ \\
\hline Direct Trucking & $2^{\prime} 020 \mathrm{CHF}$ \\
\hline
\end{tabular}

Shuttle-train $\longrightarrow \mathrm{SWL} \longrightarrow$ Trucking

cost model by changing the transport distances between terminals and shunting yards and by revising the average train length to account for the improved bundling of container flows. The effects of the business model improvements proposed by SBB Cargo were integrated directly into the model (improved efficiency of the wagon usage by shorter round-trip times, decreasing transhipment costs in hinterland terminals). The improvements from rolling stock, production schemes were integrated by changing the input data for the railway production processes (e.g., number of wagons per train, transport distances, shunting times etc.). The model used a three step approach to estimate the costs for the transport of one container on its entire trip.

In step 1, the total costs for a single transport segment (per train / per barge / per truck) were calculated. Then the segment costs for a single container were worked out by dividing the total segment cost by the number of containers. In the final step, the total trip costs for a single container were calculated by adding the costs for all transport segments. In rail transport, each shunting process was considered as a new transport segment (the shunting segments consisted of: collection: siding -> shunting yard; mainline operation: shunting yard -> shunting yard; distribution: shunting yard -> siding).

Table 1 presents the elements of the transport chan influenced by the specific improvements and Table 2 presents the components of the transport cost model used in this research.

The authors defined the basic input data including production schemes, train formation, the time needed for shunting etc. The cost rates and calculations were made by hwh Consulting using their transport cost model $[27,28]$. The authors then used the cost model results to evaluate the cost reductions for New Swiss Split compared to today's Swiss
Split. As a part of this evaluation, the effects of these improvements on the break even distance between truck-distribution and rail-distribution were also estimated.

\subsection{Analysis results}

The cost model was used to analyse the total costs for the transport of a single container from the port of Rotterdam to Switzerland. The transport costs for the shuttle train from Rotterdam to the Swiss hinterland terminal remained unaffected as Swiss Split does not cover or influence this part of the transport chain. Thus five alternatives for a container distribution to Switzerland remain.

Four of them include a shuttle-train transport to Basel:

- New Swiss Split (new Basel terminal);

- Truck via the new Basel terminal;

- Existing Swiss Split;

- Trucking via existing terminals;

One of them does not include a Shuttle train:

- Direct trucking (from Rotterdam).

The results were used to compare the feasibility of New Swiss Split to the existing Swiss Split and the distribution by truck. The analysis examined the entire transport chain from the seaport to the recipient in Switzerland.

The round trip transport costs of an average maritime container (1.5 TEU, 16 t) from Rotterdam to two example destinations: Lausen (approximately $30 \mathrm{~km}$ from Basel) and Orbe (approximately $200 \mathrm{~km}$ from Basel) were considered. The
Fig. 17 Transport costs per container from Rotterdam to Orbe (ETH Zurich)

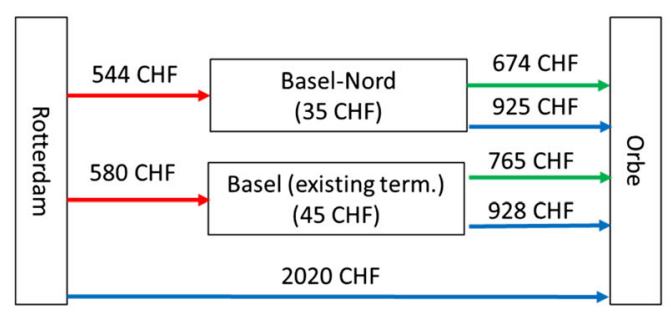

\begin{tabular}{|l|r|}
\hline Transport route & Overall Costs \\
\hline Optimized Swiss Split & 1'253 CHF \\
\hline Trucking via BS-Nord & $1^{\prime} 504 \mathrm{CHF}$ \\
\hline Swiss Split today & 1'390 CHF \\
\hline $\begin{array}{l}\text { Trucking via existing } \\
\text { terminals }\end{array}$ & $1^{\prime} 553 \mathrm{CHF}$ \\
\hline Direct Trucking & 2'020 CHF \\
\hline
\end{tabular}




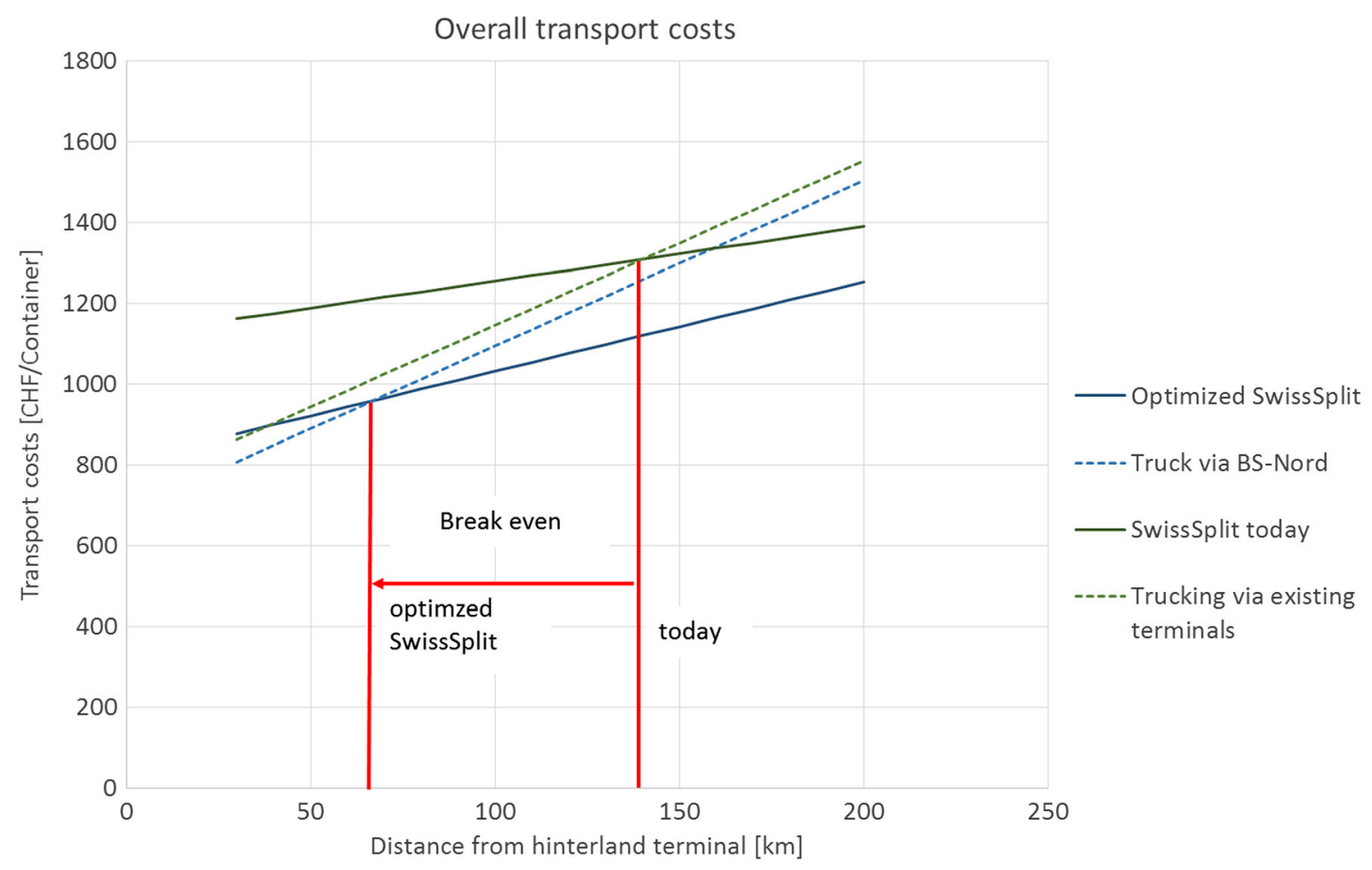

Fig. 18 Break even distance between Swiss Split and truck distribution (ETH Zurich)

analysis was completed using a transport cost model developed by hwh Consulting. Figures 16 and 17 present the results of the cost analysis.

The costs for the container distribution within the Swiss SWL network are quite high compared to the shuttle train transports from Rotterdam to Basel. Two main reasons for the differences in cost could be identified:

1. The cost level for train operation in general and especially the salaries in Switzerland are at least twice as high as in other European countries like Germany or the Netherlands

2. The operation of the shuttle train is quite efficient as it is a full train loaded with 80 TEUs and doesn't need any shunting processes between Rotterdam and Basel. The SWL transport includes the transfer of the wagon from the hinterland terminal to the shunting yard, the shunting process within the shunting yard, the train from the shunting yard to the regional shunting point, the shunting at the regional shunting point and the distribution and delivery of the wagons to the final recipients' sidings. Here the trains are comparably short (10 to 30 wagons) and the sidings are served individually wagon by wagon.

The authors also calculated the break even distance between Swiss Split and truck distribution by interpolating the results for the Lausen and Orbe case studies. The break even distance was found to decrease from 140 to $70 \mathrm{~km}$ (Fig. 18).
As shown in Fig. 18, even for quite short distances like Lausen (30 km), the improved Swiss Split becomes quite competitive to truck distribution.

\section{Conclusions and recommendations for further research}

The evaluated results show that the New Swiss Split concept would lead to a significant improvement in the overall feasibility of container distribution by SWL in Switzerland. The results show that using SWL for the final distribution is competitive even if it includes trucking between the transhipment terminal and the final recipient for relatively short distances of about $70 \mathrm{~km}$.

The next step would be to apply the planned improvements. The new container wagons are now being tested in operation to determine if further adaptions are required to meet customers' expectations. SBB Cargo will introduce the new production scheme for SWL in 2017. The new terminal Basel-Nord and the new business model will be introduced in the following years. In summary, with the implementation of these improvements, the (New) Swiss Split will remain competitive and will support the basic utilization of the SWL network.

Additional research especially regarding the further development of SWL production using optimization algorithms, which take capacity restrictions within densely operated railway networks like Switzerland into account is needed. 
Acknowledgments The further development of New Swiss Split is part of the Viable Single Wagonload (ViWaS) project and is co-financed by the European Commission within the 7th framework programme.

Open Access This article is distributed under the terms of the Creative Commons Attribution 4.0 International License (http:// creativecommons.org/licenses/by/4.0/), which permits unrestricted use, distribution, and reproduction in any medium, provided you give appropriate credit to the original author(s) and the source, provide a link to the Creative Commons license, and indicate if changes were made.

\section{References}

1. Mancera A, Bruckmann D, Weidmann U (2015) A holistic approach to measure quality of service in freight transport networks. In: Clausen U, Friedrich H, Thaller C, Geider C (eds) Commercial transport, Proceedings of the 2nd interdisciplinary conference on production, logistics and traffic, Springer International Publishing, p 287-302

2. Bruckmann D, Fumasoli T, Galonske N, Weidmann U (2013) ViWaS-viable single wagonload production schemes, 10th world congress on railway research, paper-ID 565, Sydney

3. Bruckmann D, Dober P, Fumasoli T, Mancera A, Saabel I, Weidmann U (2014) Mit dem Container bis ins Anschlussgleis Der neue SwissSplit-Wagen. Eisenbahntechnische Rundschau 63(9):169-173

4. König R, Hecht M (2012) Weissbuch Innovativer Eisenbahngüterwagen 2030, Die Zukunftsinitiative "5L" als Grundlage für Wachstum im Schienengüterverkehr, Available from: https://www.schienenfzg.tu-berlin.de/fileadmin/fg62 /Dokumente/Downloads/Weissbuch_Innovativer Eisenbahngueterwagen_2030.pdf

5. Eschweiler P, Hecht M (2013) Einfluss des Wagens auf den Marktanteil des Schienengüterverkehrs - Weissbuch Eisenbahngüterwagen 2030; Jahrbuch Logistik 2013. Verlag: free beratung Gesellschaft für Kommunikation im Marketing mbH. Unit Logistik, p 24-27

6. Notteboom T (2008) Bundling of freight flows and hinterland network developments. In: Konings R, Priemus H, Nijkamp P (eds) The future of intermodal freight transport, operations, design and policy. Edwar Elgar, Cheltenham

7. Rutten B (1998) The design of a terminal network for intermodal transport. Transp Logist 1(4):279-298

8. Arnold P, Peeters D, Isabelle T (2004) Modelling a rail/road intermodal transportation system. Transp Res Part E Logist Transp Rev 40(3):255-270

9. Holweg M, Disney S, Holmström J, Smaros J (2005) Supply chain collaboration: making sense of the strategy continuum. Eur Manag J 23(2):170-181

10. Stank TP, Goldsby TJ (2000) A framework for transportation decision making in an integrated supply chain. Supply Chain Manag Int J 5(2):71-78

11. Bock S (2010) Real-time control of freight forwarder transportation networks by integrating multimodal transport chains. Eur J Oper Res 200(3):733-746
12. Krajewska MA, Kopfer $\mathrm{H}$ (2006) Collaborating freight forwarding enterprises, request allocation and profit sharing. OR Spectrum 28(3):301-317

13. Saeed N (2013) Cooperation among freight forwarders: mode choice and intermodal freight transport. Res Transp Econ 42(1):77-86

14. Moll S (2012) Productivity improvements for freight railways through collaborative transport planning, Dissertation, Eidgenössische Technische Hochschule ETH Zürich, No. 20610

15. Wittenbrink P, Hagenlocher S, Heizmann B (2013) Neue Formen einer Organisation des Einzelwagenverkehrs. Zeitschrift für Verkehrswissenschaft 94(1):24-49

16. Islam DMZ (2014) Barriers to and enablers for European rail freight transport for integrated door-to-door logistics services, part 2: enablers for multimodal rail freight transport. Transport Probl 9(4):513

17. Marin A, Salmeron J (1996) Tactical design of rail freight network. Part I: exact and heuristic methods. Eur J Oper Res 90(1):26-44

18. Marin A, Salmeron J (1996) Tactical design of rail freight network. Part II: local search methods with statistical analysis. Eur J Oper Res 94(1):43-53

19. Ceselli A, Gatto M, Lübbecke ME, Nunkesser M, Schilling H (2008) Optimizing the cargo express network of Swiss federal railways. Transp Sci 42(4):450-465

20. Bruckmann D (2007) Entwicklung einer Methode zur Abschätzung des containerisierbaren Aufkommens im Einzelwagenverkehr und Optimierung der Produktionsstruktur, phD-Thesis, Schriftenreihe des Instituts für Verkehrswesen und Verkehrsbau der Universität Duisburg-Essen, 5

21. Ickert L, Maibach M, Bertschmann D, Eichler M, Balmer C, Bruckmann D, Frank P (2012) Marktanalyse und Marktprognose Schienengüterverkehr, Bern, available from website: http://www. voev.ch/de/Service/Downloadsindex.php?section= downloads\&download=2719

22. Verein Deutscher Ingenieure (1992) Transloading installations with industrial trucks for general cargo, VDI 2360, May 1992, Available from: Beuth Verlag, Berlin

23. Ickert L, Maibach M, Bieler C, Bruckmann D, Fumasoli T (2012) Grossterminalstudie, Beurteilung der Terminalprojekte Gateway Limmattal und Basel-Nord, Schlussbericht, Bern, available from website: http://www.voev.ch/de/Service/Downloadsindex. php? section $=$ downloads\&download $=2719$

24. Erwin Rutishauser Management Support (2014) Mediation Weiterentwicklung Terminallandschaft, Schlussbericht, Bundesamt für Verkehr

25. Bruckmann D, Jackson CE, Ballmer M, Weidmann U (2014) Optimization of SWL production schemes using an agent based simulation, EURO - ZEL 2014, 22nd International Symposium, Žilina

26. Bruckmann D, Fumasoli T (2012) Prozessorientierte Ansätze für eine qualitative Nutzenermittlung von Innovationen im Schienengüterverkehr, III. Internationales Fachsymposium Moderner Schienengüterverkehr und Intermodaler Verkehr 2012, Berlin

27. Wittenbrink P (2011) Transportkostenmanagement im Strassengüterverkehr, Grundlagen - Optimierungspotenziale Green Logistics. Gabler-Verlag, Wiesbaden

28. Wittenbrink P, Hagenlocher S, Heizmann B (2012) Kalkulation von Schienengüterverkehrsleistungen. Prima 2012(3):30-31 